\title{
Three-dimensional ultrasound in gynecological clinical practice
}

\author{
This article was published in the following Dove Press journal: \\ Reports in Medical Imaging \\ 23 January 2012 \\ Number of times this article has been viewed
}

\author{
Juan Luis Alcázar \\ María Aubá \\ Begoña Olartecoechea \\ Department of Obstetrics and \\ Gynecology, Clinica Universidad \\ de Navarra, University of Navarra, \\ Pamplona, Spain
}

Correspondence: Juan Luis Alcázar Department of Obstetrics and Gynecology, Clinica Universidad de Navarra, Avenida Pio XII, 36, 31008 Pamplona, Spain

Tel +34948 255400

Fax +34948296500

Email jlalcazar@unav.es
Abstract: Three-dimensional ultrasound is an imaging technique that is being introduced into clinical practice in several medical specialties. Although this technique is unlikely to replace the two-dimensional ultrasound, its role as a diagnostic tool is being explored. In fact, in the field of gynecology there has been a steady increase in the number of papers published in the last few years. These applications include: imaging the uterus, uterine cavity, adnexa, and pelvic floor as well as reproductive medicine, such as the prediction of IVF success or ovarian hyperstimulation syndrome. The aim of this paper is to review the current status of threedimensional ultrasound in clinical practice in gynecology.

Keywords: three-dimensional, ultrasound, gynecology

\section{Introduction}

Conventional two-dimensional ultrasound (2D-US) is widely used in gynecological practice and it may be considered as an essential imaging technique for diagnosing uterine and adnexal pathology. ${ }^{1}$

In the last decade, three-dimensional ultrasound (3D-US) has become available for clinical use. Initially focused on obstetrical imaging, its role in gynecology is currently being explored.

Although this technique has been applied in almost every field in gynecology such as pelvic floor, ${ }^{2-4}$ reproductive medicine, ${ }^{5-7}$ and uterine and adnexal pathology, ${ }^{8,9}$ we shall focus on those issues more frequently seen in a gynecological clinic: uterine and adnexal pathology.

We performed a comprehensive computerized search to identify all articles published in English literature related to 3D-US in uterine and adnexal pathology. The search was performed in the MEDLINE database from January 1996 to November 2011 using different combinations of the following keywords: three-dimensional, ultrasound, uterine Müllerian anomalies, uterine congenital anomalies, ovarian tumor, adnexal masses, adenomyosis, myoma, uterine bleeding, sonohysterography, ovarian cancer, and endometrial cancer.

One author (JLA) read all abstracts of articles identified through the computer search. To be included for complete assessment, the articles had to provide the following information: (1) aim, (2) study design, (3) type of data collection, (4) sampling method, (5) 3D-US methodology used.

Case reports, review articles, and Letters to Editor as well as non-English language articles were excluded. submit your manuscript | www.dovepress.com

Dovepress

http:dx.doi.org// 0.2147/RMI.S21963
Reports in Medical Imaging 2012:5 1-13

(C) 2012 Alcázar et al, publisher and licensee Dove Medical Press Ltd. This is an Open Access article which permits unrestricted noncommercial use, provided the original work is properly cited. 
In studies comparing 3D-US and 2D-US, two-by-two tables for calculating sensitivity and specificity for each method were constructed whenever possible from raw data reported in those studies.

Cross-references of all selected articles were checked for other articles meeting inclusion criteria.

\section{Technical notes}

A detailed description of technical issues regarding 3D-US is beyond the scope of this article. There are several published papers that address this question and reading is advised. ${ }^{10-12}$ However, we shall briefly describe some technical considerations.

Three-dimensional ultrasound requires the use of dedicated 3D transducers. These are available from most high-brand ultrasound device manufacturers. When these probes are activated, the transducer elements automatically sweep through the region of interest (ROI) selected by the operator (the so-called "volume box") while the probe is held stationary. The operator can select a constant speed of sweep through the ROI using machine settings. Lower speeds result in higher resolution, and a larger volume box leads to longer acquisition time. Once the $3 \mathrm{D}$ volume is acquired it can be digitally stored and transferred via DICOM (Nema, Rosslyn, VA) to a personal computer for further assessment with dedicated software.

The 3D volume can be manipulated in several ways. Probably the most used and useful display is multiplanar display, which simultaneously shows three orthogonal planes (axial, longitudinal, and coronal) allowing navigation through these three planes. The coronal plane is almost impossible to obtain in conventional vaginal ultrasound and difficult to obtain in abdominal ultrasound but easy to reconstruct using 3D ultrasound. This is a significant benefit, at least theoretically, compared to conventional ultrasound. It is possible to switch to any desired plane and an accurate spatial orientation is virtually always possible (Figure 1).

Other displays for 3D-US are:

1. Tomographic ultrasound imaging that presents images like magnetic resonance imaging does (Figure 2).

2. Surface rendering that shows surfaces (Figure 3).

3. "Niche" mode that shows an "in-block" imaging of the ROI allowing a 3D spatial orientation (Figure 4).

4. "Omni-view" mode that shows one perpendicular plane over the other making the imaging simpler (Figure 5).

5. "Inversion" mode that shows as "opaque" what is a fluidfilled structure giving a more precise idea of the shape of the cystic cavity (Figure 6).

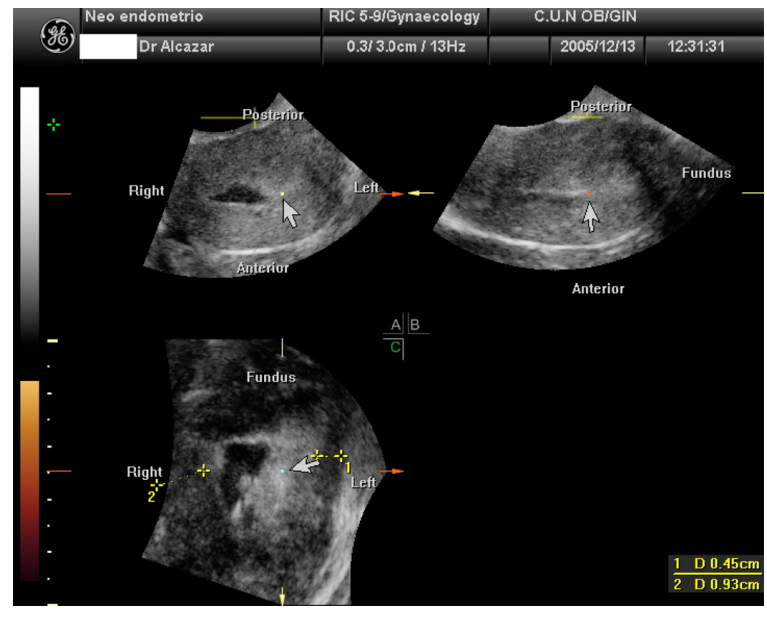

Figure I Three-dimensional transvaginal ultrasound depicting multiplanar display in a case of endometrial cancer. Coronal plane is shown in the lower left on the screen. The tumor is located in the left uterine wall infiltrating the lateral wall (arrow).

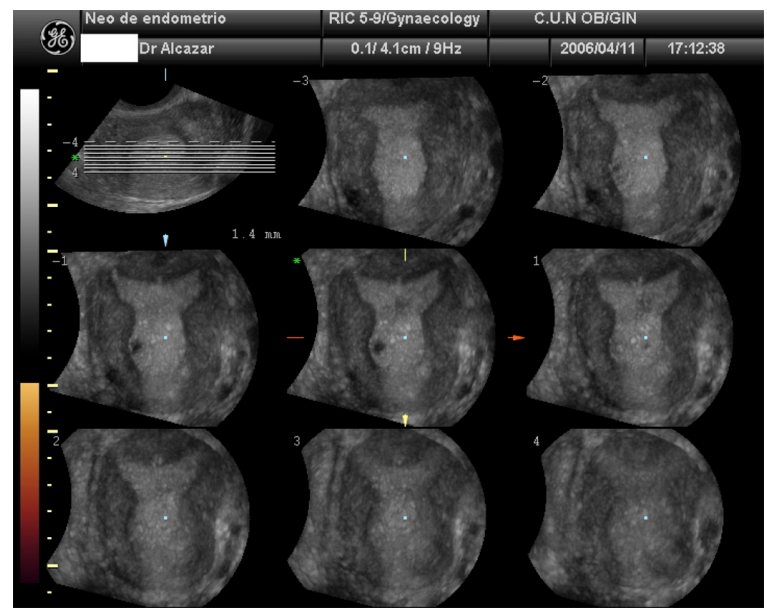

Figure 2 Tomographic ultrasound imaging (TUI) that depicts the coronal plane of a uterus with endometrial cancer. A lateral, barrel-shaped endometrial thickening is easily seen close to the internal cervical os.

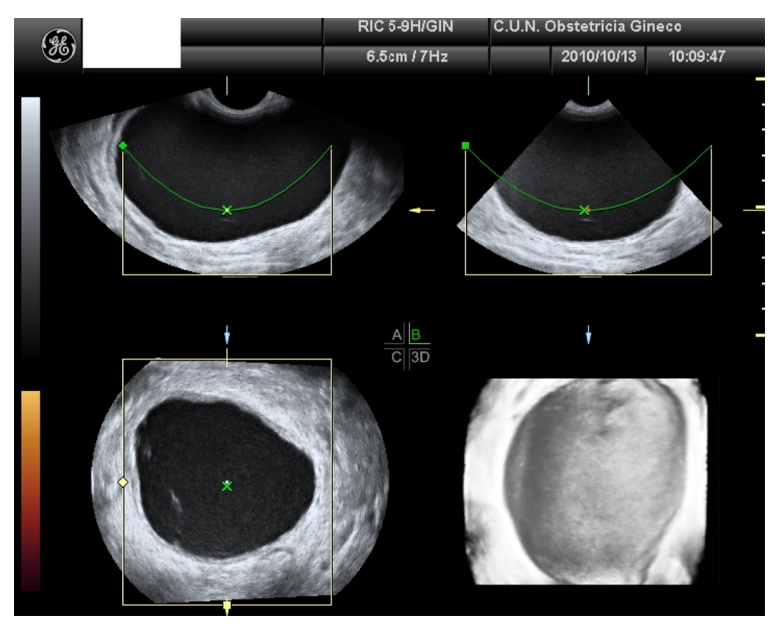

Figure 3 Three-dimensional ultrasound showing the surface rendering of the internal wall from an ovarian cyst. A smooth internal surface can be seen. 


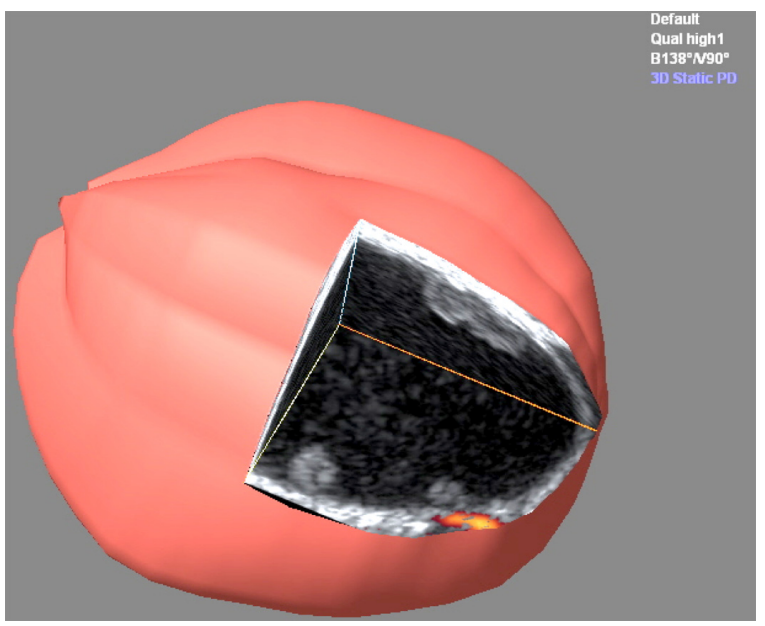

Figure 4 Three-dimensional ultrasound from an ovarian cyst seen depicting the "niche" mode. The cyst exhibits three papillary projections. A vessel is also seen within the cyst wall. Niche mode shows this vessel is not entering the papillary projection.

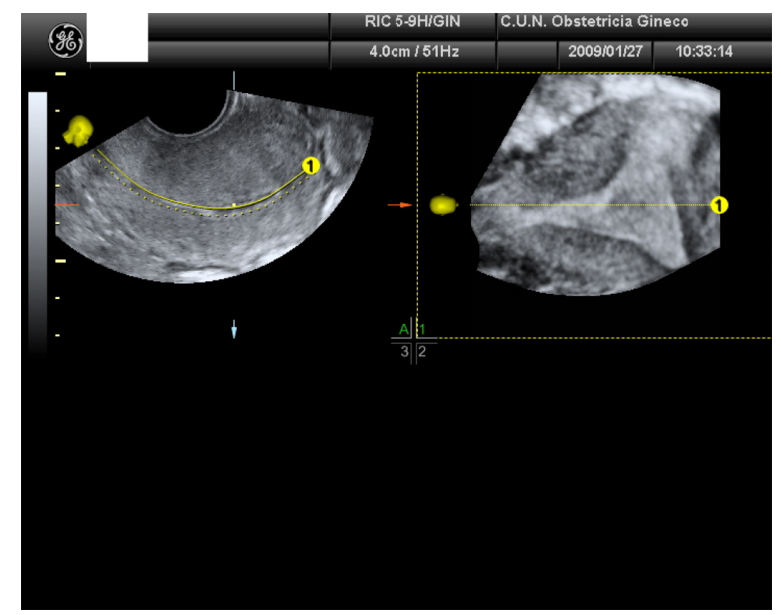

Figure 5 Omni-view mode from a normal uterus. This mode allows visualization of the coronal plane, like the examiner was seeing through the cervix (see yellow head). Coronal plane (right) is perpendicular to the yellow line (left). This mode allows a perfect spatial orientation.

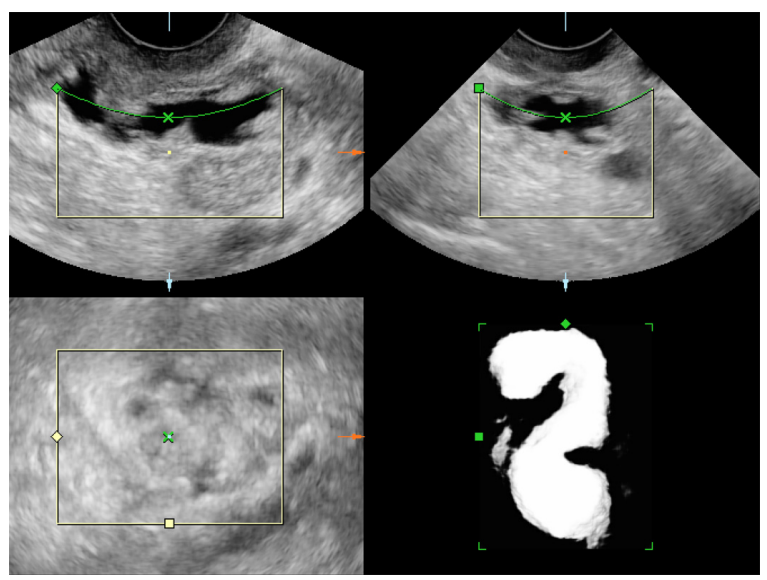

Figure 6 Inversion mode from an hydrosalpinx. The fluid content is depicted as opaque and the "S" shape of the hydrosalpinx is easily recognizable.
Another important ability of 3D-US is volume calculation even in irregularly shaped structures using the Virtual Organ Computer-aided Analysis (VOCAL ${ }^{\mathrm{TM}}$; GE Healthcare, Wein, Austria) $)^{13}$ and Automated Volume calculation (SonoAVC; General Electric Company, Schenectady, NY) specifically designed for automatic volume estimation of cystic structures (Figure 7). This method has been demonstrated to be more accurate than $2 \mathrm{D}$ uterine and ovarian volume estimation. ${ }^{14-19}$

The addition of power Doppler to three-dimensional ultrasound allows the assessment of organ/tissue vascularity. By using 3D power Doppler angiography (3D-PDA) it is possible to reconstruct the vascular tree within a given ROI. This reconstructed vascular tree can be subjectively analyzed. ${ }^{20}$

On the other hand, using VOCAL software three-dimensional power Doppler-derived indices can be calculated from a given ROI. ${ }^{21}$ These indices were named Vascularization Index (VI), Flow Index (FI), and Vascularization-Flow Index (VFI). These indices are based and related to the total and relative amount of power Doppler information within the ROI. The VI is expressed as a percentage and measures the ratio between the number of color voxels and total number of voxels within the ROI. The FI is unitless and is the average color value of all color voxels. VI is thought to reflect the amount of vessels within the ROI, whereas FI is thought to reflect the intensity of flow within those vessels at the time of 3D sweep. VFI is just a mathematical relationship between VI and FI and it is thought to represent both blood flow and vascularization. Actually, it is not well known what these indices are really measuring. ${ }^{22}$ According to in vitro and in vivo studies, VI seems to be related to the number of vessels and flow, whereas there are doubts about the meaning of FI. ${ }^{23-25}$

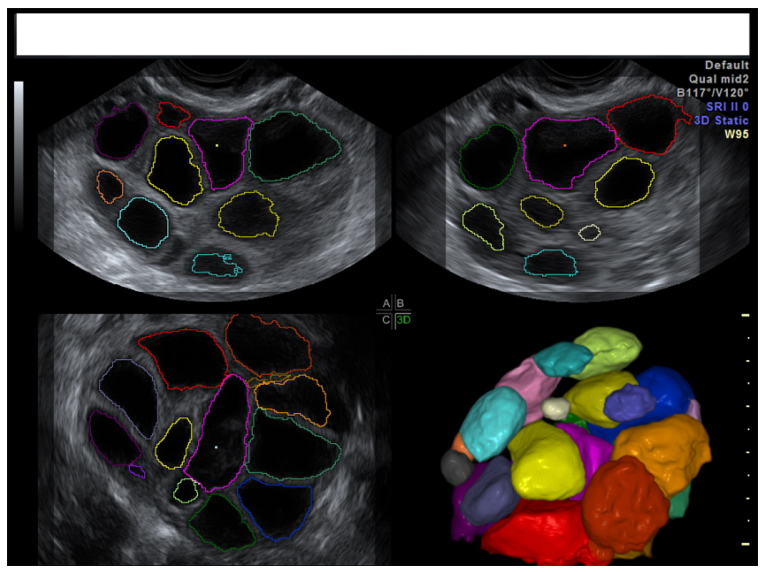

Figure 7 Sono-AVC mode allows individual identification and automatic volume calculation of cystic structures. In this case several follicles within a stimulated ovary are seen, each one depicted in a different color. 
Furthermore, these indices are significantly affected by machine settings, such as gain and pulse repetition frequency as well as tissue attenuation. ${ }^{26-28}$ For these reasons, there is concern about their use in clinical practice..$^{29,30}$

Finally, analysis can be done off-line and not in realtime, which avoids the need for immediate reporting. This technique has been shown to improve workflow in an ultrasound laboratory ${ }^{31}$ and may also be useful for teaching and second opinion. ${ }^{32}$

\section{Three-dimensional ultrasound in uterine pathology}

\section{Uterine Müllerian anomalies}

Although conventional 2D US has shown a good performance for discriminating different types of uterine anomalies, ${ }^{33}$ it is highly dependent on the expertise of the examiner, ${ }^{34}$ and it is limited by the difficulty to obtain the coronal plane of the uterus in most cases. Several studies have demonstrated the advantages of 3D-US (Table 1).

Jurkovic and colleagues compared 2D-US, 3D-US, and hysterosalpingography (HSG) for diagnosing congenital uterine malformations. They used HSG as gold standard and found that 3D-US was more accurate than 2D-US for diagnosing arcuate uterus and had a higher positive predictive value for diagnosing major anomalies, especially for differentiating subseptated and bicornuate uteri. ${ }^{35}$

Raga and coworkers evaluated the diagnostic accuracy of 3D-US for diagnosing congenital uterine anomalies using laparoscopy and HSG as the gold standard. They found that 3D-US correctly classified $92 \%$ of all anomalies. ${ }^{36} \mathrm{Wu}$ and colleagues performed a similar study, but using laparoscopy and hysteroscopy as the gold standard. Three-dimensional ultrasound detected $92 \%$ of septated uteri and $100 \%$ bicornuate uteri. ${ }^{37}$

More recent studies have confirmed these results and definitions for different anomalies have been proposed. ${ }^{38-42}$
Salim and coworkers have shown that $3 \mathrm{D}-\mathrm{US}$ is a reproducible method for diagnosing congenital uterine anomalies. ${ }^{43}$ Bermejo et al have demonstrated that 3D-US is as accurate as magnetic resonance imaging. ${ }^{44}$

For these reasons 3D-US is currently considered as the first step imaging technique for diagnosing uterine congenital anomalies $^{45}$ (Figures 8-10).

The potential clinical value of using 3D-US for diagnosing congenital uterine anomalies has been shown in two studies, which both found that screening uterine malformations by means of 3D-US may improve reproductive outcomes. ${ }^{46,47}$

\section{Intracavitary uterine lesions}

Uterine abnormal bleeding is a common complaint in gynecologic clinics. Two-dimensional saline infusion sonohysterography (2D-SIS) has been demonstrated to be a very useful tool for diagnosing intracavitary abnormalities. ${ }^{48-50}$

Several studies have tried to answer the question whether three-dimensional sonohysterography (3D-SIS) would add useful information to 2D-SIS.

La Torre and coworkers found that 3D-SIS was more specific (100\%) than 2D-SIS (94\%) for diagnosing endometrial polyps in a series of only 16 women suspected of having such a pathology in conventional 2D transvaginal ultrasound. ${ }^{51}$

Lev-Toaff and colleagues found that 3D-SIS added valuable information to 2D-SIS in $69 \%$ of their cases and in $92 \%$ of the cases when compared to HSG. ${ }^{52}$ However, their sample size was small (only 13 patients underwent both 2D-SIS and 3D-SIS). The advantages they found were: confirming suggestive findings on 2D-SIS or HSG and establishing the location, number, and attachments of endometrial polyps, submucous fibroids, and adhesions. Similar conclusions were drawn by Ghate et al in a series of 42 women. They found that 3D-SIS added valuable information for assessing the uterine fundus. ${ }^{53}$ However, in these two studies, specificity for each method

Table I Diagnostic performance of 3D-US for uterine Müllerian anomalies

\begin{tabular}{|c|c|c|c|c|}
\hline \multirow[t]{2}{*}{ Author } & \multicolumn{2}{|l|}{ 2D-US } & \multicolumn{2}{|l|}{ 3D-US } \\
\hline & Sensitivity & Specificity & Sensitivity & Specificity \\
\hline Jurkovic et al ${ }^{35}$ & $100 \%$ & $95 \%$ & $100 \%$ & $100 \%$ \\
\hline Raga et $\mathrm{al}^{36}$ & & & $100 \%$ & $100 \%$ \\
\hline Wu et $\mathrm{al}^{37}$ & & & $93 \%$ & $100 \%$ \\
\hline Kupesić et al ${ }^{38}$ & & & $100 \%$ & $100 \%$ \\
\hline La Torre et $\mathrm{al}^{39}$ & & & $100 \%$ & $85 \%$ \\
\hline Momtaz and Ebrashy ${ }^{40}$ & $55 \%$ & $95 \%$ & $97 \%$ & $96 \%$ \\
\hline Ghi et $\mathrm{al}^{4 !}$ & & & $100 \%$ & $100 \%$ \\
\hline Caliskan et $\mathrm{al}^{42}$ & $42 \%$ & $81 \%$ & $100 \%$ & $94 \%$ \\
\hline
\end{tabular}




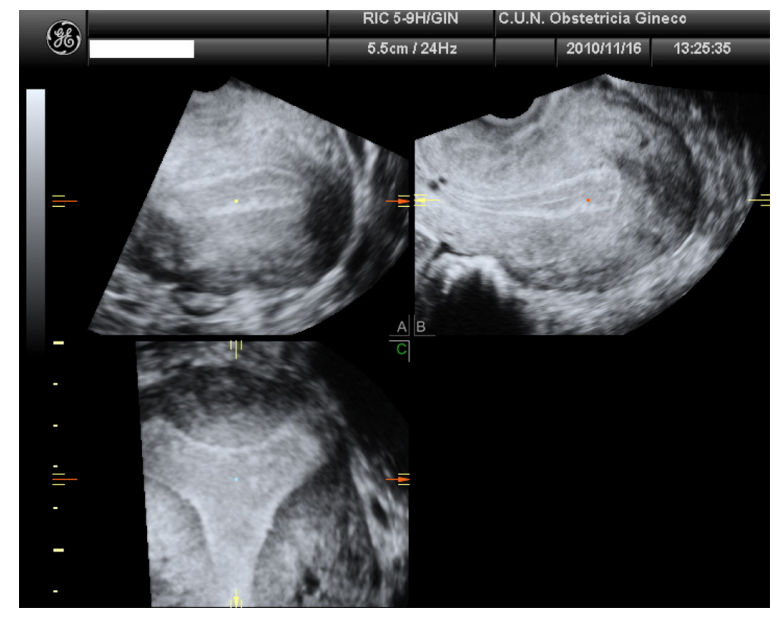

Figure 8 Three-dimensional transvaginal ultrasound from an arcuate uterus.

could not be calculated because for women with normal findings on ultrasound, no further tests were performed.

Sylvestre et al evaluated the diagnostic accuracy of 3D-SIS for diagnosing intracavitary lesions in 209 infertile women. They found that when compared to hysteroscopy, 3D-SIS had a sensitivity of $100 \%$ and a positive predictive value of $92 \%$. However, these figures were not different than those for 2D-SIS (98\% and 95\%, respectively).$^{54}$ As in the previously mentioned papers, specificity for each method could not be calculated because of lack of gold standard test information in women with normal findings.

De Kroon and coworkers compared 3D-SIS and 2D-SIS in 49 patients suspected of having intracavitary abnormalities. They concluded that 2D-SIS and 3D-SIS had similar performance (Sensitivity: 95\% for both techniques. Specificity: $100 \%$ for $3 \mathrm{D}$-SIS versus $88 \%$ for $2 \mathrm{D}$-SIS), but 3D-SIS added "relevant clinical" information in $7 \%$ of their patients. ${ }^{55}$

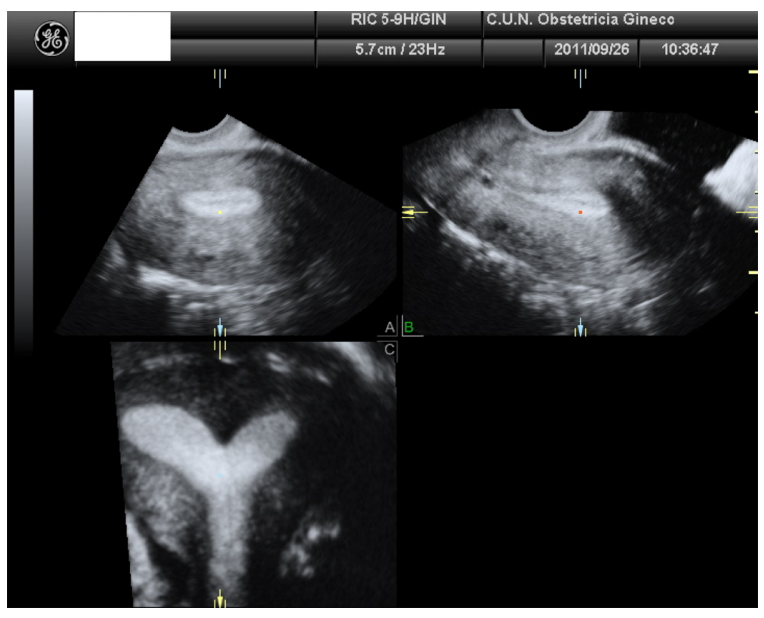

Figure 9 Three-dimensional transvaginal ultrasound from a subseptated uterus.

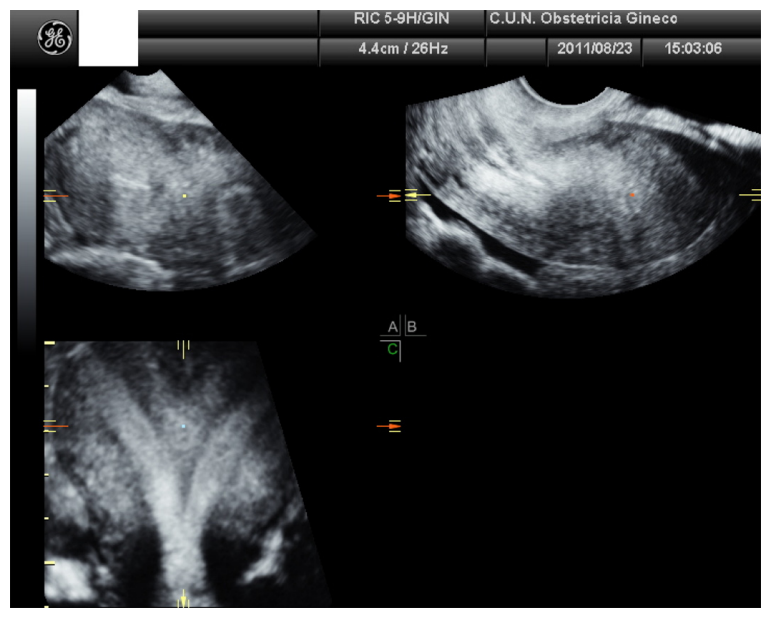

Figure 10 Three-dimensional transvaginal ultrasound from a septated uterus.

Makris et al evaluated 124 women with suspected intracavitary lesions by $3 \mathrm{D}-$ SIS $^{56}$ using hysteroscopy and endometrial biopsy as the gold standard. The technique failed in three women due to cervical stenosis. They found that sensitivity and specificity for this technique were $91.9 \%$ and $98.8 \%$, respectively.

Terry et al compared 3D-SIS with 2D-SIS using hysteroscopy as the gold standard as well. 3D-SIS was more specific than 2D-SIS (75\% versus 62\%) with similar sensitivity ( $93 \%$ versus $99 \%$ ), but differences did not reach statistical significance. ${ }^{57}$

Opolskiene and colleagues did not find differences between 2D-SIS and 3D-SIS for predicting malignancy in women presenting with postmenopausal bleeding. ${ }^{58}$

In summary, 3D-SIS seems not to be superior to 2D-SIS for diagnosing intracavitary lesions but helps to reinforce diagnosis and may add some information in some cases (Figure 11).

One interesting issue is the assessment of submucous myomas. Salim et al demonstrated that 3D-SIS had a similar accuracy to hysteroscopy for classifying submucous fibroids. They found that agreement between both techniques was high. ${ }^{59}$ Furthermore, 3D-SIS is reproducible among different observers for such a classification. ${ }^{60}$

A recent study has shown that 3D-SIS may be useful for predicting complete hysteroscopic resection of submucous myomas. ${ }^{61}$

\section{Adenomyosis}

Adenomyosis is a relatively frequent disease that is difficult to diagnose. ${ }^{62}$ Transvaginal ultrasound has shown an acceptable diagnostic performance comparable to magnetic resonance imaging. ${ }^{62}$ 


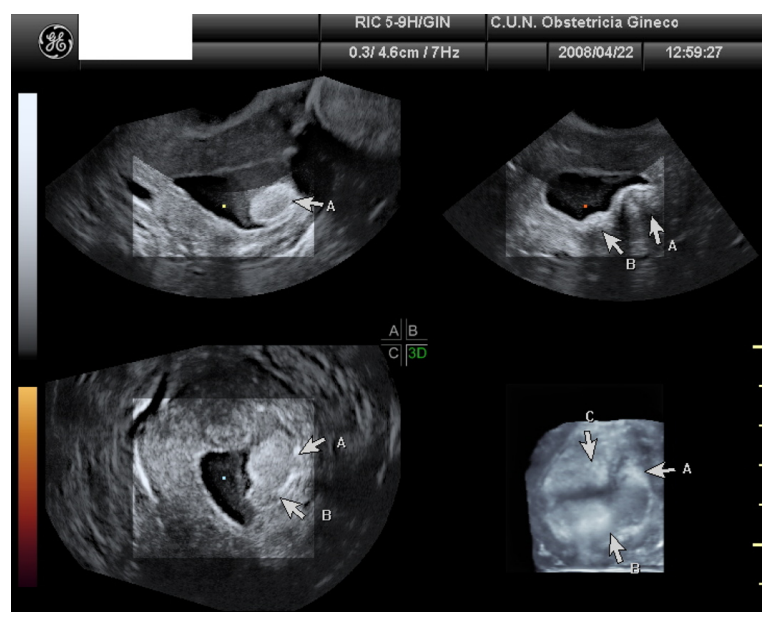

Figure II Three-dimensional saline infusion sonohysterography. The internal uterine cavity surface is shown. Three lesions can be seen (arrows A, B, and C). Combination with multiplanar display allows spatial orientation. In fact, lesion $C$ is not shown in $2 \mathrm{D}$ planes but it is seen on surface rendering.

Only one study has assessed the role of 3D-US for diagnosing adenomyosis. Exacoustos et al evaluated 72 premenopausal women scheduled for a hysterectomy for their benign condition. ${ }^{63}$ Thirty-two of them had histologically proven uterine adenomyosis. They found that the uterine coronal plane was useful for assessing the "junctional zone," the uterine compartment at the endomyometrial interface that is thought to be involved in the pathogenesis of adenomyosis. The junctional zone can be visualized as a hypoechoic area surrounding the endometrium and can be measured as the distance from the basal endometrium to the internal layer of the outer myometrium (Figure 12). They found that 3D-US had a better sensitivity than 2D-US ( $91 \%$ versus $75 \%$ ) with similar specificity ( $88 \%$ versus $90 \%$ ) for diagnosing adenomyosis.

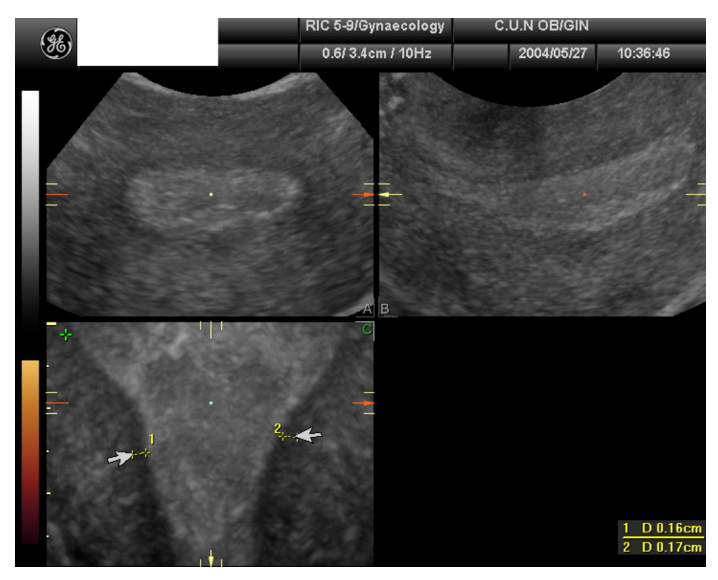

Figure 12 Three-dimensional ultrasound from a uterus that shows the junctional zone in coronal plane (arrows). It can be measured and its integrity may also be assessed.
More recently, Naftalin et al have demonstrated that assessment visualization and measurement of the uterine junctional zone by 3D-US had good intra- and inter-observer reproducibility. ${ }^{64}$

\section{Endometrial pathology}

Endometrial thickness measurement is a well-established method for identifying women with higher risk for endometrial cancer in postmenopausal bleeding. ${ }^{65}$ However, although sensitive enough, endometrial thickness is non-specific. ${ }^{66}$ Three-dimensional ultrasound allows the assessment of endometrial volume (Figure 13). This is clinically attractive since theoretically endometrial volume may reflect more accurately the amount of endometrial tissue.$^{67}$ In fact, endometrial volume estimation has shown to be reproducible in tumoral endometria. ${ }^{68}$

Several studies have evaluated the role of 3D-US endometrial volume assessment as compared to endometrial thickness measurement for predicting endometrial cancer in women with postmenopausal bleeding (Table 2).

Two studies show that endometrial volume is more sensitive than endometrial thickness for diagnosing endometrial cancer. Gruboeck et al analyzed the diagnostic value of endometrial volume for diagnosing endometrial cancer in a series of 97 patients with postmenopausal bleeding. ${ }^{69}$ They reported that an endometrial volume $\geq 13.0 \mathrm{~mL}$ would detect all endometrial cancers with a false-positive rate of $1.2 \%$. They included all patients without regarding endometrial thickness but only eleven cases had endometrial cancer. Mansour et al reached similar conclusions in a series of 170 women with postmenopausal bleeding. ${ }^{70}$ However, these authors reported that the best cut-off for endometrial volume

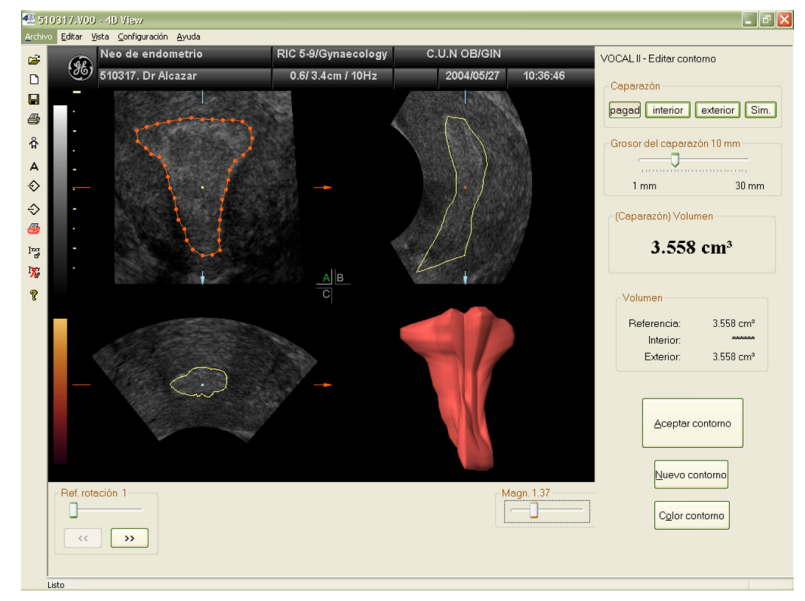

Figure I3 Endometrial volume estimation by VOCAL method using threedimensional ultrasound. 
Table 2 Endometrial volume compared with endometrial thickness for diagnosing endometrial cancer in women with postmenopausal bleeding

\begin{tabular}{|c|c|c|c|c|c|c|c|c|c|}
\hline \multirow[t]{2}{*}{ Author } & \multirow[t]{2}{*}{$\mathbf{N}$} & \multirow[t]{2}{*}{ EC prevalence } & \multirow[t]{2}{*}{ Cut-off } & \multicolumn{3}{|l|}{ ET } & \multicolumn{3}{|l|}{ EV } \\
\hline & & & & AUC & Sens & Spec & AUC & Sens & Spec \\
\hline \multirow[t]{2}{*}{ Gruboeck et al ${ }^{69}$} & 97 & $11 \%$ & ET $15.0 \mathrm{~mm}$ & NA & $83 \%$ & $88 \%$ & NA & & \\
\hline & & & $\mathrm{EV} / 3 \mathrm{cc}$ & & & & & $100 \%$ & $99 \%$ \\
\hline \multirow[t]{2}{*}{ Mansour et al ${ }^{70}$} & 170 & $16 \%$ & NA & NA & $79 \%$ & $91 \%$ & & & \\
\hline & & & $\mathrm{EV} 1.35 \mathrm{~mL}$ & & & & NA & $100 \%$ & $71 \%$ \\
\hline \multirow[t]{2}{*}{ Yaman et $\mathrm{al}^{71}$} & 213 & $20 \%$ & ET 7.0 mm & 0.85 & $100 \%$ & $43 \%$ & & & \\
\hline & & & $\mathrm{EV} 2.70 \mathrm{~mL}$ & & & & 0.89 & $100 \%$ & $69 \%$ \\
\hline \multirow[t]{2}{*}{ Odeh et $\mathrm{al}^{72, *}$} & 56 & $20 \%$ & ET $5.5 \mathrm{~mm}$ & 0.70 & $97 \%$ & $12 \%$ & & & \\
\hline & & & $\mathrm{EV} 3.56 \mathrm{~mL}$ & & & & 0.73 & $93 \%$ & $36 \%$ \\
\hline \multirow[t]{2}{*}{ Mercé et $\mathrm{al}^{73, \dagger}$} & 84 & $65 \%$ & ET $12.1 \mathrm{~mm}$ & NA & $69 \%$ & $55 \%$ & & & \\
\hline & & & EV $6.86 \mathrm{~mL}$ & & & & 0.64 & $63 \%$ & $69 \%$ \\
\hline \multirow[t]{2}{*}{ Alcázar and Galván $74, \neq$} & 99 & $44 \%$ & ET 7.6 mm & 0.75 & $90 \%$ & $36 \%$ & & & \\
\hline & & & $\mathrm{EV} 2.30 \mathrm{~mL}$ & & & & 0.85 & $93 \%$ & $62 \%$ \\
\hline \multirow[t]{2}{*}{ Opolskiene et $\mathrm{al}^{75, \neq}$} & 62 & $20 \%$ & ET $11.8 \mathrm{~mm}$ & 0.82 & $85 \%$ & $71 \%$ & & & \\
\hline & & & EV $5.30 \mathrm{~mL}$ & & & & 0.78 & $69 \%$ & $88 \%$ \\
\hline
\end{tabular}

Notes: *Endometrial hyperplasia and cancer included in the same "pathologic" group; †retrospective study assessing only women with endometrial hyperplasia and cancer; "prospective study including only women with thickened endometrium.

Abbreviations: EC, endometrial cancer; ET, endometrial thickness; EV, endometrial volume; sens, sensitivity; spec, specificity; NA, not available; AUC, area under the curve for ROC curves.

was $1.35 \mathrm{~mL}$ with a sensitivity of $100 \%$ and a false-positive rate of $29 \%$.

On the other hand, Yaman et al found that endometrial volume was more specific than endometrial thickness in a series of 213 women, 42 with endometrial cancer. ${ }^{71}$ In this study, the best cut-off for endometrial volume was $2.7 \mathrm{~mL}$ (100\% sensitivity and 69\% specificity). Other studies have shown similar findings, but all of them offered different cut-off values for endometrial volume. ${ }^{72-74}$ In contrast, Opolskiene et al did not find differences between endometrial volume and thickness in terms of sensitivity and specificity for diagnosing endometrial cancer in women with postmenopausal bleeding and an endometrial thickness $>4.5 \mathrm{~mm}^{75}$

One recent retrospective study has assessed the endometrial/uterine corporeal volume ratio (EV/UCV) in a series of 160 women with postmenopausal bleeding. ${ }^{76}$ This study concluded that an EV/UCV ratio $>0.017$ was more accurate in the prediction of endometrial malignancy.

In summary, current information regarding the role of endometrial volume for predicting endometrial cancer in postmenopausal women seems to be controversial and further research with better designed studies and larger series is needed.

Regarding the role of 3D-PDA in this clinical setting, five studies have been published (Table 3).

Odeh et al reported that all three 3D-PD indices were significantly higher in women with endometrial cancer as compared with those with benign pathology ${ }^{72}$ However, they did not compare with conventional 2D-PD and the specificity reported was low. Mercé et al found that 3D-PD indices were significantly higher in women with endometrial cancer as compared with those with endometrial hyperplasia, ${ }^{73}$ but the study was retrospective, the series was small, and it did not include other endometrial pathology. Alcázar et al also found that 3D-PD indices were significantly higher in women with endometrial cancer as compared with those with benign pathology ${ }^{74}$ but this study included only women with endometrial thickness above $5 \mathrm{~mm}$ and did not compare 3D results with conventional $2 \mathrm{D}$ color Doppler.

Opolskiene et al reported data in a series of women with postmenopausal bleeding and endometrial thickness $>4.5 \mathrm{~mm}^{75}$ They concluded that, although 3D-PD

Table 3 ROC curves for endometrial 3D vascular indices for diagnosing endometrial cancer

\begin{tabular}{llll}
\hline Author & Vascularization index & Flow index & Vascularization-flow index \\
\hline${\text { Odeh et } \mathrm{al}^{72}}^{73}$ & 0.62 & 0.63 & 0.62 \\
Mercé et al $^{73}$ & 0.79 & 0.78 & 0.80 \\
Alcázar and Galván $^{74}$ & 0.90 & 0.70 & 0.87 \\
Opolskiene et al $^{75}$ & 0.82 & $0.8 \mathrm{I}$ & 0.82 \\
\hline
\end{tabular}


indices were significantly higher in women with endometrial cancer as compared with those with benign pathology, this technique adds little information to endometrial thickness or volume.

Lieng et al analyzed a small series of women with endometrial polyps $(n=17)$ and endometrial cancer $(n=17)$ comparing 3D-PD indices within the lesions before and after contrast-enhanced examination. ${ }^{77}$ They did not find differences between the groups in the 3D-PD indices.

Only two studies have evaluated the use of 3D-US in women known as having an endometrial cancer.

Alcázar et al described and analyzed the diagnostic performance of a new method for assessing myometrial infiltration preoperatively based on $3 \mathrm{D}$-ultrasound. ${ }^{78}$ This new approach was based on a three-dimensional virtual navigation through the uterus for detecting the deepest point of myometrial infiltration in a series of 96 women with endometrial cancer. The most interesting finding from this study was the negative predictive value (100\%) for deep infiltration reported using this approach. However, the false-positive rate reported was $39 \%$.

Galván et al assessed the correlation between intratumoral 3D-PDA indices and several histological tumor characteristics in a series of 99 women with endometrial cancer. ${ }^{79}$ In their analysis, endometrial volume and vascularization index were independently associated with myometrial infiltration and tumor stage, vascularization index was independently associated with tumor grade, and endometrial volume correlated with lymph node metastases. However, these data can be considered as preliminary and need to be validated.

\section{Three-dimensional ultrasound in adnexal pathology}

Several studies have been published aiming to determine whether morphological 3D-US is better than conventional 2D-US for diagnosing ovarian cancer in women with adnexal masses (Table 4).
Bonilla-Musoles et al reported a series of 76 women in whom the same examiner performed both 3D-US and 2D-US. ${ }^{80}$ They found that $3 \mathrm{D}-\mathrm{US}$ is able to show internal papillary projections missed when using conventional $2 \mathrm{D}-\mathrm{US}$ in $7 \%$ of the cases. 3D-US was more sensitive than $2 \mathrm{D}-\mathrm{US}$ (100\% versus $80 \%)$, with similar specificity.

Hata et al reported a series of 20 women in whom the different examiners performed both $3 \mathrm{D}-\mathrm{US}$ and $2 \mathrm{D}-\mathrm{US}{ }^{81}$ They found that $3 \mathrm{D}$-US was more specific than $2 \mathrm{D}-\mathrm{US}$ (92.3\% versus $38.4 \%$ ) with similar sensitivity.

Alcázar et al reported a series of 41 women diagnosed as having complex adnexal masses on 2D-US. Two different examiners performed 3D-US and 2D-US. ${ }^{82}$ In this study $3 \mathrm{D}-\mathrm{US}$ was not better than 2D-US for predicting ovarian malignancy, but it helped to reinforce the examiner's diagnostic impression. This same group reported a second series with similar results to the previous one. ${ }^{83}$

Laban et al in a series of 50 masses found that 3D-US had a higher sensitivity and specificity than $2 \mathrm{D}-\mathrm{US}{ }^{84}$

Some studies have assessed the role of 3D-PDA for discriminating benign from malignant adnexal masses.

Cohen et al aimed to determine if 3D-PD could improve the specificity of 2D-US morphological ultrasound in a series of 71 complex adnexal masses on 2D morphologic transvaginal ultrasound. ${ }^{85}$ They did not use $2 \mathrm{D}$ conventional color Doppler or 2D power Doppler. In their approach, they combined 2D and 3D morphological features with 3D-PDA evaluation of blood flow tumor location, considering a tumor as malignant in the presence of complex morphological pattern and central (in papillary projections and/or septations) blood flow location. They concluded that the addition of 3D-PDA improved the specificity of 2D morphologic transvaginal ultrasound (75\% versus 54\%), with similar sensitivity. These results are not surprising and can be also achieved by using a simpler technique such as 2D power Doppler. ${ }^{86-88}$

Three-dimensional power Doppler reconstruction of the tumoral vascular tree allows the assessment of microaneurysms, arteriovenous shunts, abnormal vessels branching, tortuosity, and vessel caliber changes, all of them

Table 4 Three-dimensional versus two-dimensional morphologic ultrasound for diagnosing ovarian cancer

\begin{tabular}{|c|c|c|c|c|c|c|c|}
\hline \multirow[t]{2}{*}{ Author } & \multirow[t]{2}{*}{$\mathbf{N}$} & \multirow[t]{2}{*}{ OC prevalence } & \multicolumn{2}{|c|}{ Sensitivity } & \multicolumn{2}{|c|}{ Specificity } & \multirow[t]{2}{*}{$P$ value } \\
\hline & & & 3D & 2D & 3D & 2D & \\
\hline Bonilla-Musoles et al ${ }^{80}$ & 76 & $7 \%$ & $100 \%$ & $80 \%$ & $100 \%$ & $99 \%$ & $<0.05$ \\
\hline Hata et $\mathrm{a}^{81}$ & 20 & $25 \%$ & $100 \%$ & $100 \%$ & $92 \%$ & $38 \%$ & $<0.05$ \\
\hline Alcázar et al ${ }^{82}$ & 49 & $48 \%$ & $100 \%$ & $90 \%$ & $78 \%$ & $61 \%$ & NS \\
\hline Laban et $\mathrm{al}^{84}$ & 50 & $62 \%$ & $90 \%$ & $81 \%$ & $84 \%$ & $79 \%$ & NA \\
\hline Alcázar et $\mathrm{al}^{83}$ & 82 & $33 \%$ & $93 \%$ & $89 \%$ & $98 \%$ & $94 \%$ & NS \\
\hline
\end{tabular}

Abbreviations: OC, ovarian cancer; 2D, two dimensional ultrasound; 3D, three dimensional ultrasound; NS, statistically non-significant; NA, not available. 
Table 5 3D-PD tumor vascular tree assessment for diagnosing ovarian cancer

\begin{tabular}{|c|c|c|c|c|c|c|c|}
\hline \multirow[t]{2}{*}{ Author } & \multirow[t]{2}{*}{$\mathbf{N}$} & \multirow[t]{2}{*}{ OC prevalence } & \multicolumn{2}{|c|}{ Sensitivity } & \multicolumn{2}{|c|}{ Specificity } & \multirow[t]{2}{*}{$P$ value } \\
\hline & & & 3D-PD & 2D & 3D-PD & $2 \mathrm{D}$ & \\
\hline Kurjak et $\mathrm{al}^{90, \dagger}$ & 120 & $9 \%$ & $100 \%$ & $91 \%$ & $99 \%$ & $97 \%$ & NA \\
\hline Kurjak et $\mathrm{a}^{91, \dagger}$ & 90 & $10 \%$ & $100 \%$ & $89 \%$ & $99 \%$ & $37 \%$ & NA \\
\hline Kupesić and Kurjak ${ }^{92, \$ * *}$ & 45 & $27 \%$ & $58 \%$ & - & $97 \%$ & - & NA \\
\hline Laban et a ${ }^{84, t, *}$ & 50 & $62 \%$ & $100 \%$ & $100 \%$ & $74 \%$ & $74 \%$ & NA \\
\hline Sladkevicius et $\mathrm{al}^{93, \neq}$ & 104 & $26 \%$ & $96 \%$ & $100 \%$ & $96 \%$ & $90 \%$ & NS \\
\hline Alcázar et al ${ }^{94, \S}$ & 39 & $51 \%$ & $90 \%$ & $95 \%$ & $74 \%$ & $74 \%$ & NS \\
\hline Dai et al95,§,* & 36 & $83 \%$ & $77 \%$ & $97 \%$ & $50 \%$ & $50 \%$ & $<0.05$ \\
\hline Mansour et a $\left.\right|^{96, \S}$ & 400 & $62 \%$ & $88 \%$ & $94 \%$ & $89 \%$ & $73 \%$ & NS \\
\hline
\end{tabular}

Notes: ${ }^{\dagger}$ Criteria for malignancy suspicion: scoring system combining morphology and 3D-PD features; ${ }^{\ddagger}$ criteria for malignancy suspicion: logistic model combining morphology and 3D-PD features; ' criteria for malignancy suspicion: only 3D-PD features; *only "complex" masses included in the study.

Abbreviations: OC, ovarian cancer; 2D, two dimensional ultrasound; 3D-PD, three dimensional power Doppler; NS, statistically non-significant; NA, not available.

characteristics of malignant tumors. ${ }^{89}$ The first group to evaluate the vascular tree for predicting ovarian malignancy in adnexal masses was the group of Kurjak et al. ${ }^{90-92}$ Although the authors "concluded" that 3D-PD was better than 2D-PD, no statistical analysis was reported supporting such a conclusion.

Several subsequent studies, all of them using similar criteria for malignancy suspicion, reported similar findings: 3D-PD vascular tree assessment adds little to conventional ultrasound. ${ }^{84,93-96}$ Furthermore, this approach is only moderately reproducible. ${ }^{93,94}$ These studies are summarized in Table 5.

The use of 3D-PDA derived indices for discriminating benign from malignant adnexal masses was first proposed by Alcázar et al. ${ }^{97}$ In their report they proposed the assessment of 3D-PDA indices within the most suspicious vascularized area from the tumor in vascularized solid or cystic-solid masses, which are the most difficult to determine by conventional 2D-US and power Doppler. In a series of 69 vascularized solid and cystic-solid masses they found that all 3D-PDA indices were significantly higher in ovarian cancer as compared with benign tumors. This group demonstrated that this approach is reproducible. ${ }^{98}$

Testa et al reported similar findings using different software in a series of 24 women with solid ovarian masses. ${ }^{99}$
Geomini et al reported data from a series of 181 women with adnexal masses. ${ }^{100}$ This study included any kind of mass diagnosed at transvaginal ultrasound and performed the vascular assessment from the whole tumor. They found that FI, but not VI and VFI, was significantly higher in malignant masses.

Jokubkiene et al proposed a modified approach based on the use of a virtual 5-cc spherical sampling from the most vascularized area from the tumor. They also found that 3D-PDA vascular indices were higher in ovarian cancer as compared with benign tumors, ${ }^{101}$ but they concluded that this information was of little value as compared with gray-scale analysis performed by an experienced examiner. However, this study included any type of mass and not only those difficult to classify, which could be a source of bias. ${ }^{102}$

Kudla et al proposed using a 1-cc spherical sampling and also found that 3D-PDA indices were significantly higher in malignant tumors. ${ }^{103}$

Only one study has not shown differences in 3D-PD indices between benign and malignant ovarian tumors. ${ }^{104}$ However, the series was too small (only 17 cases).

Alcázar and Prka compared manual and spherical sampling and concluded that both methods are comparable and that spherical sampling is faster to perform. However, 5-cc

Table 6 3D-PD vascular sampling for diagnosing ovarian cancer

\begin{tabular}{|c|c|c|c|c|c|c|c|}
\hline \multirow[t]{2}{*}{ Author } & \multirow[t]{2}{*}{$\mathbf{N}$} & \multirow[t]{2}{*}{ OC prevalence } & \multicolumn{2}{|c|}{ Sensitivity } & \multicolumn{2}{|c|}{ Specificity } & \multirow[t]{2}{*}{$P$ value } \\
\hline & & & 3D-PD & 2D & 3D-PD & 2D & \\
\hline Geomini et al ${ }^{100, \dagger}$ & 181 & $20 \%$ & $57 \%$ & $91 \%$ & $85 \%$ & $63 \%$ & $<0.05$ \\
\hline Jokubkiene et $\mathrm{al}^{101, \uparrow}$ & 106 & $25 \%$ & $100 \%$ & $100 \%$ & $92 \%$ & $90 \%$ & $<0.05$ \\
\hline Alcázar and Guerriero ${ }^{102, *, \S}$ & 143 & $74 \%$ & $95 \%$ & $100 \%$ & $33 \%$ & $0 \%$ & $<0.05$ \\
\hline Kudla and Alcázar ${ }^{108, *, \S}$ & 138 & $82 \%$ & $91 \%$ & $100 \%$ & $77 \%$ & $0 \%$ & $<0.05$ \\
\hline
\end{tabular}

Notes: †Criteria for malignancy suspicion: logistic system combining morphology and 3D-PD indices; ${ }^{\S}$ criteria for malignancy suspicion: only 3D-PD indices; *only "complex" masses included in the study.

Abbreviations: OC, ovarian cancer; 2D, two dimensional ultrasound; 3D-PD, three dimensional power Doppler. 
spherical sampling cannot be used in about $20 \%$ of tumors, usually because of the small size of some lesions. ${ }^{105}$

Several studies have shown that whatever the approach used, manual or spherical sampling, reproducibility is high between observers. ${ }^{101,103,105,106}$

Two prospective studies have shown that 3D-PDA may significantly decrease the false-positive rate of malignancy in vascularized solid and cystic-solid adnexal masses without decreasing significantly sensitivity. ${ }^{107,108}$ The results of these studies are summarized in Table 6.

In summary, the use of 3D-PDA in adnexal masses seems to be encouraging. However, this technique is significantly affected by some factors such as machine settings and attenuation and needs to be standardized. ${ }^{109}$ For this reason, its use cannot be introduced to general practice.

Some authors have proposed new approaches to overcome this problem, ${ }^{110-112}$ however, further prospective studies are needed.

\section{Summary}

Three-dimensional ultrasound is an imaging technique that allows unique ways for assessing uterine and adnexal pathology. From the clinical point of view it can be considered that, in general, there is a lack of robust data to support routine use of 3D-US. However, some authors consider this technique as the standard imaging technique for diagnosing uterine Müllerian anomalies. It seems to provide additional information for identifying intracavitary uterine lesions.

Its role in endometrial and adnexal pathology is controversial and further research is needed in these areas.

\section{Disclosure}

The authors report no conflicts of interest in this work.

\section{References}

1. Timor-Tritsch I, Goldstein S. Ultrasound in Gynecology. 2nd ed. New York: Elsevier; 2006.

2. Dietz HP. Pelvic floor ultrasound: a review. Am J Obstet Gynecol. 2010;202(4):321-334.

3. Santoro GA, Wieczorek AP, Dietz HP, et al. State of the art: an integrated approach to pelvic floor ultrasonography. Ultrasound Obstet Gynecol. 2011;37(4):381-389.

4. Santoro GA, Wieczorek AP, Shobeiri SA, et al. Interobserver and interdisciplinary reproducibility of 3D endovaginal ultrasound assessment of pelvic floor anatomy. Int Urogynecol J. 2011;22(1): $53-59$.

5. Coyne L, Jayaprakasan K, Raine-Fenning N. 3D ultrasound in gynecology and reproductive medicine. Womens Health (Lond Engl). 2008;4(5):501-516.

6. Mercé LT, Barco MJ, Bau S, Troyano JM. Prediction of ovarian response and IVF/ICSI outcome by three-dimensional ultrasonography and power Doppler angiography. Eur J Obstet Gynecol Reprod Biol. 2007;132(1):93-100.
7. Alcázar JL. Three-dimensional ultrasound assessment of endometrial receptivity: a review. Reprod Biol Endocrinol. 2006;4:56.

8. Jurkovic D. Three-dimensional ultrasound in gynecology: a critical evaluation. Ultrasound Obstet Gynecol. 2002;19(2):109-117.

9. Alcázar JL, Jurado M. Three-dimensional ultrasound for assessing women with gynecological cancer: a systematic review. Gynecol Oncol. 2011;120(3):340-346.

10. Nelson TR, Pretorius DH, Hull A, Riccabona M, Sklansky MS, James G. Sources and impact of artifacts on clinical three-dimensional ultrasound imaging. Ultrasound Obstet Gynecol. 2000;16(4):374-383.

11. Bega G, Lev-Toaff AS, O'Kane P, Becker E Jr, Kurtz AB. Threedimensional ultrasonography in gynecology: technical aspects and clinical applications. J Ultrasound Med. 2003;22(11):1249-1269.

12. Levaillant J. Value of 3D-4D sonography in fetal and gynecological ultrasound examination: principles and indications. J Radiol. 2006;87 (12 Pt 2):1969-1992.

13. Raine-Fenning NJ, Clewes JS, Kendall NR, Bunkheila AK, Campbell BK, Johnson IR. The interobserver reliability and validity of volume calculation from three-dimensional ultrasound datasets in the in vitro setting. Ultrasound Obstet Gynecol. 2003;21(3):283-291.

14. Kyei-Mensah A, Zaidi J, Pittrof R, Shaker A, Campbell S, Tan SL. Transvaginal three-dimensional ultrasound: accuracy of follicular volume measurements. Fertil Steril. 1996;65(2):371-376.

15. Riccabona M, Nelson TR, Pretorius DH, Davidson TE. In vivo threedimensional sonographic measurement of organ volume: validation in the urinary bladder. J Ultrasound Med. 1996;15(9):627-632.

16. Wu MH, Tang HH, Hsu CC, Wang ST, Huang KE. The role of three-dimensional ultrasonographic images in ovarian measurement. Fertil Steril. 1998;69(6):1152-1155.

17. Farrell T, Leslie JR, Chien PF, Agustsson P. The reliability and validity of three dimensional ultrasound volumetric measurements using an in vitro balloon and in vivo uterine model. BJOG. 2001;108(6):573-582.

18. Yaman C, Jesacher K, Polz W. Accuracy of three-dimensional transvaginal ultrasound in uterus volume measurements: comparison with two-dimensional ultrasound. Ultrasound Med Biol. 2003;29(12): 1681-1684.

19. Bozdag G, Salman MC, Mumusoglu S, Yapici Z, Gunalp S. Is ovarian volume estimation reliable when compared with true volume? Am J Obstet Gynecol. 2011;206(1):44.e1-4.

20. Crade M, Berman M, Chase D. Three-dimensional tissue block ultrasound in ovarian tumors. Ultrasound Obstet Gynecol. 2005;26(6):683-686.

21. Pairleitner H, Steiner H, Hasenoehrl G, Staudach A. Three-dimensional power Doppler sonography: imaging and quantifying blood flow and vascularization. Ultrasound Obstet Gynecol. 1999;14(2): 139-143.

22. Alcázar JL. Three-dimensional power Doppler derived vascular indices: what are we measuring and how are we doing it? Ultrasound Obstet Gynecol. 2008;32(4):485-487.

23. Raine-Fenning NJ, Nordin NM, Ramnarine KV, et al. Determining the relationship between three-dimensional power Doppler data and true blood flow characteristics: an in-vitro flow phantom experiment. Ultrasound Obstet Gynecol. 2008;32(4):540-550.

24. Jones NW, Hutchinson ES, Brownbill P, et al. In vitro dual perfusion of human placental lobules as a flow phantom to investigate the relationship between fetoplacental flow and quantitative 3D power doppler angiography. Placenta. 2009;30(2):130-135.

25. Morel O, Pachy F, Chavatte-Palmer P, et al. Correlation between uteroplacental three-dimensional power Doppler indices and true uterine blood flow: evaluation in a pregnant sheep model. Ultrasound Obstet Gynecol. 2010;36(5):635-640.

26. Raine-Fenning NJ, Nordin NM, Ramnarine KV, et al. Evaluation of the effect of machine settings on quantitative three-dimensional power Doppler angiography: an in-vitro flow phantom experiment. Ultrasound Obstet Gynecol. 2008;32(4):551-559.

27. Schulten-Wijman MJ, Struijk PC, Brezinka C, De Jong N, Steegers EA. Evaluation of volume vascularization index and flow index: a phantom study. Ultrasound Obstet Gynecol. 2008;32(4):560-564. 
28. Martins WP, Raine-Fenning NJ, Ferriani RA, Nastri CO. Quantitative three-dimensional power Doppler angiography: a flow-free phantom experiment to evaluate the relationship between color gain, depth and signal artifact. Ultrasound Obstet Gynecol. 2010;35(3): 361-368.

29. Welsh A. The questionable value of VOCAL indices of perfusion. Ultrasound Obstet Gynecol. 2010;36(1):126-127.

30. Martins WP. Three-dimensional power Doppler: validity and reliability. Ultrasound Obstet Gynecol. 2010;36(5):530-533.

31. Mercé LT, Alcázar JL, Barco MJ, et al. Can 3-dimensional ultrasonography change ultrasonographic examination in Spain? Prog Obstet Ginecol. 2008;51:256-264.

32. Alcázar JL, Iturra A, Sedda F, et al. Three-dimensional volume off-line analysis as compared to real-time ultrasound for assessing adnexal masses. Eur J Obstet Gynecol Biol Reprod. In press. 2012. doi: http:// dx.doi.org/10.1016/j.ejogrb.2011.12.002.

33. Nicolini U, Bellotti M, Bonazzi B, Zamberletti D, Candiani GB. Can ultrasound be used to screen uterine malformations? Fertil Steril. 1987;47(1):89-93.

34. Randolph JF Jr, Ying YK, Maier DB, Schmidt CL, Riddick DH, Randolph JR Jr. Comparison of real-time ultrasonography, hysterosalpingography, and laparoscopy/hysteroscopy in the evaluation of uterine abnormalities and tubal patency. Fertil Steril. 1986;46(5) $828-832$

35. Jurkovic D, Geipel A, Gruboeck K, Jauniaux E, Natucci M, Campbell S. Three-dimensional ultrasound for the assessment of uterine anatomy and detection of congenital anomalies: a comparison with hysterosalpingography and two-dimensional sonography. Ultrasound Obstet Gynecol. 1995;5(4):233-237.

36. Raga F, Bonilla-Musoles F, Blanes J, Osborne NG. Congenital Mullerian anomalies: diagnostic accuracy of three-dimensional ultrasound. Fertil Steril. 1996;65(3):523-528.

37. Wu MH, Hsu CC, Huang KE. Detection of congenital mullerian duct anomalies using three-dimensional ultrasound. J Clin Ultrasound 1997;25(9):487-489.

38. Kupesić S, Kurjak A, Skenderovic S, Bjelos D. Screening for uterine abnormalities by three-dimensional ultrasound improves perinatal outcome. J Perinat Med. 2002;30(1):9-17

39. La Torre R, Prosperi Porta R, Franco C, et al. Three-dimensional sonography and hysterosalpingosonography in the diagnosis of uterine anomalies. Clin Exp Obstet Gynecol. 2003;30(4):190-192.

40. Momtaz MM, Ebrashy AM. Three-dimensional ultrasonography in the evaluation of the uterine cavity. Middle East Fertil Soc J. 2007; 12:41-46.

41. Ghi T, Casadio P, Kuleva M, et al. Accuracy of three-dimensional ultrasound in diagnosis and classification of congenital uterine anomalies. Fertil Steril. 2009;92(2):808-813.

42. Caliskan E, Ozkan S, Cakiroglu Y, Sarisoy HT, Corakci A, Ozeren S. Diagnostic accuracy of real-time 3D sonography in the diagnosis of congenital Mullerian anomalies in high-risk patients with respect to the phase of the menstrual cycle. J Clin Ultrasound. 2010;38(3):123-127.

43. Salim R, Woelfer B, Backos M, Regan L, Jurkovic D. Reproducibility of three-dimensional ultrasound diagnosis of congenital uterine anomalies. Ultrasound Obstet Gynecol. 2003;21:578-582.

44. Bermejo C, Martínez Ten P, Cantarero R, et al. Three-dimensional ultrasound in the diagnosis of Müllerian duct anomalies and concordance with magnetic resonance imaging. Ultrasound Obstet Gynecol. 2010;35(5):593-601.

45. Deutch TD, Abuhamad AZ. The role of 3-dimensional ultrasonography and magnetic resonance imaging in the diagnosis of müllerian duct anomalies: a review of the literature. J Ultrasound Med. 2008; 27(3):413-423.

46. Woelfer B, Salim R, Banerjee S, Elson J, Regan L, Jurkovic D. Reproductive outcomes in women with congenital uterine anomalies detected by three-dimensional ultrasound screening. Obstet Gynecol. 2001; 98(6):1099-1103.
47. Jayaprakasan K, Chan YY, Sur S, Deb S, Clewes JS, Raine-Fenning NJ. Prevalence of uterine anomalies and their impact on early pregnancy in women conceiving after assisted reproduction treatment. Ultrasound Obstet Gynecol. 2011;37(6):727-732.

48. Berridge DL, Winter TC. Saline infusion sonohysterography: technique, indications, and imaging findings. J Ultrasound Med. 2004; 23(1):97-112.

49. de Kroon CD, Jansen FW. Saline infusion sonography in women with abnormal uterine bleeding: an update of recent findings. Curr Opin Obstet Gynecol. 2006;18(6):653-657.

50. Elsayes KM, Pandya A, Platt JF, Bude RO. Technique and diagnostic utility of saline infusion sonohysterography. Int $J$ Gynaecol Obstet. 2009;105(1):5-9.

51. La Torre R, De Felice C, De Angelis C, Coacci F, Mastrone M, Cosmi EV. Transvaginal sonographic evaluation of endometrial polyps: a comparison with two dimensional and three dimensional contrast sonography. Clin Exp Obstet Gynecol. 1999;26(3-4):171-173.

52. Lev-Toaff AS, Pinheiro LW, Bega G, Kurtz AB, Goldberg BB. Three-dimensional multiplanar sonohysterography: comparison with conventional two-dimensional sonohysterography and X-ray hysterosalpingography. J Ultrasound Med. 2001;20(4):295-306.

53. Ghate SV, Crockett MM, Boyd BK, Paulson EK. Sonohysterography: do $3 \mathrm{D}$ reconstructed images provide additional value? AJR Am J Roentgenol. 2008;190(4):W227-W233.

54. Sylvestre C, Child TJ, Tulandi T, Tan SL. A prospective study to evaluate the efficacy of two- and three-dimensional sonohysterography in women with intrauterine lesions. Fertil Steril. 2003;79(5):1222-1225.

55. De Kroon CD, Louwe LA, Trimbos JB, Jansen FW. The clinical value of 3-dimensional saline infusion sonography in addition to 2-dimensional saline infusion sonography in women with abnormal uterine bleeding. J Ultrasound Med. 2004;23(11):1433-1440.

56. Makris N, Kalmantis K, Skartados N, Papadimitriou A, Mantzaris G, Antsaklis A. Three-dimensional hysterosonography versus hysteroscopy for the detection of intracavitary uterine abnormalities. Int $J$ Gynaecol Obstet. 2007;97(1):6-9.

57. Terry S, Banks E, Harris K, Duvivier R, Dar P. Comparison of 3-dimensional with 2-dimensional saline infusion sonohysterograms for the evaluation of intrauterine abnormalities. J Clin Ultrasound. 2009;37(5):258-262.

58. Opolskiene G, Sladkevicius P, Valentin L. Two- and three-dimensional saline contrast sonohysterography: interobserver agreement, agreement with hysteroscopy and diagnosis of endometrial malignancy. Ultrasound Obstet Gynecol. 2009;33(5):574-582.

59. Salim R, Lee C, Davies A, Jolaoso B, Ofuasia E, Jurkovic D. A comparative study of three-dimensional saline infusion sonohysterography and diagnostic hysteroscopy for the classification of submucous fibroids. Hum Reprod. 2005;20(1):253-257.

60. Lee C, Salim R, Ofili-Yebovi D, Yazbek J, Davies A, Jurkovic D. Reproducibility of the measurement of submucous fibroid protrusion into the uterine cavity using three-dimensional saline contrast sonohysterography. Ultrasound Obstet Gynecol. 2006;28(6):837-841.

61. Mavrelos D, Naftalin J, Hoo W, Ben-Nagi J, Holland T, Jurkovic D. Preoperative assessment of submucous fibroids by three-dimensional saline contrast sonohysterography. Ultrasound Obstet Gynecol. 2011;38(3):350-354.

62. Dueholm M, Lundorf E. Transvaginal ultrasound or MRI for diagnosis of adenomyosis. Curr Opin Obstet Gynecol. 2007;19(6):505-512.

63. Exacoustos C, Brienza L, Di Giovanni A, et al. Adenomyosis: threedimensional sonographic findings of the junctional zone and correlation with histology. Ultrasound Obstet Gynecol. 2011;37(4):471-479.

64. Naftalin J, Hoo W, Nunes N, Mavrelos D, Nicks H, Jurkovic D. Inter and intra-observer variability in 3D ultrasound assessment of the endometrialmyometrial junction and factors affecting its visualisation. Ultrasound Obstet Gynecol. 2011. [Epub ahead of print.] doi: 10.1002/uog.10133.

65. Smith-Bindman R, Kerlikowske K, Feldstein VA, et al. Endovaginal ultrasound to exclude endometrial cancer and other endometrial abnormalities. JAMA. 1998;280(17):1510-1517. 
66. Timmermans A, Opmeer BC, Khan KS, et al. Endometrial thickness measurement for detecting endometrial cancer in women with postmenopausal bleeding: a systematic review and meta-analysis. Obstet Gynecol. 2010;116(1):160-167.

67. Martins WP, Ferriani RA, Barra DA, et al. Reliability and validity of tissue volume measurement by three-dimensional ultrasound: an experimental model. Ultrasound Obstet Gynecol. 2007;29(2):210-214.

68. Alcázar JL, Mercé LT, Manero MG, Bau S, López-García G. Endometrial volume and vascularity measurements by transvaginal 3-dimensional ultrasonography and power Doppler angiography in stimulated and tumoral endometria: an interobserver reproducibility study. J Ultrasound Med. 2005;24(8):1091-1098.

69. Gruboeck K, Jurkovic D, Lawton F, Savvas M, Tailor A, Campbell S. The diagnostic value of endometrial thickness and volume measurements by three-dimensional ultrasound in patients with postmenopausal bleeding. Ultrasound Obstet Gynecol. 1996;8(4):272-276.

70. Mansour GM, El-Lamie IK, El-Kady MA, El-Mekkawi SF, Laban M, Abou-Gabal AI. Endometrial volume as predictor of malignancy in women with postmenopausal bleeding. Int J Gynaecol Obstet. 2007; 99(3):206-210.

71. Yaman C, Habelsberger A, Tews G, Pölz W, Ebner T. The role of three-dimensional volume measurement in diagnosing endometrial cancer in patients with postmenopausal bleeding. Gynecol Oncol. 2008;110(3):390-395.

72. Odeh M, Vainerovsky I, Grinin V, Kais M, Ophir E, Bornstein J. Threedimensional endometrial volume and 3-dimensional power Doppler analysis in predicting endometrial carcinoma and hyperplasia. Gynecol Oncol. 2007;106(2):348-353.

73. Mercé LT, Alcázar JL, López C, et al. Clinical usefulness of 3-dimensional sonography and power Doppler angiography for diagnosis of endometrial carcinoma. J Ultrasound Med. 2007;26(10):1279-1287.

74. Alcázar JL, Galván R. Three-dimensional power Doppler ultrasound scanning for the prediction of endometrial cancer in women with postmenopausal bleeding and thickened endometrium. Am J Obstet Gynecol. 2009;200(1):44. e1-e6.

75. Opolskiene G, Sladkevicius P, Jokubkiene L, Valentin L. Threedimensional ultrasound imaging for discrimination between benign and malignant endometrium in women with postmenopausal bleeding and sonographic endometrial thickness of at least $4.5 \mathrm{~mm}$. Ultrasound Obstet Gynecol. 2010;35(1):94-102.

76. Mansour GM, El-Shalakany A. Endometrial/uterine corporeal volume ratio (EV/UCV) as predictor of malignancy in women with postmenopausal bleeding. Arch Gynecol Obstet. 2011. [Epub ahead of print.]

77. Lieng M, Qvigstad E, Dahl GF, Istre O. Flow differences between endometrial polyps and cancer: a prospective study using intravenous contrast-enhanced transvaginal color flow Doppler and threedimensional power Doppler ultrasound. Ultrasound Obstet Gynecol. 2008;32(7):935-940.

78. Alcázar JL, Galván R, Albela S, et al. Assessing myometrial infiltration by endometrial cancer: uterine virtual navigation with three-dimensional US. Radiology. 2009;250(3):776-783.

79. Galván R, Mercé L, Jurado M, Mínguez JA, López-García G, Alcázar JL. Three-dimensional power Doppler angiography in endometrial cancer: correlation with tumor characteristics. Ultrasound Obstet Gynecol. 2010;35(6):723-729.

80. Bonilla-Musoles F, Raga F, Osborne NG. Three-dimensional ultrasound evaluation of ovarian masses. Gynecol Oncol. 1995;59(1):129-135.

81. Hata T, Yanagihara T, Hayashi K, et al. Three-dimensional ultrasonographic evaluation of ovarian tumours: a preliminary study. Hum Reprod. 1999;14(3):858-861.

82. Alcázar JL, Galán MJ, García-Manero M, Guerriero S. Threedimensional ultrasound morphologic assessment in complex adnexal masses a preliminary experience. J Ultrasound Med. 2003;22(3): 249-254.

83. Alcázar JL, García-Manero M, Galván R. Three-dimensional sonographic morphologic assessment of adnexal masses: a reproducibility study. J Ultrasound Med. 2007;26(8):1007-1011.
84. Laban M, Metawee H, Elyan A, Kamal M, Kamel M, Mansour G. Three-dimensional ultrasound and three-dimensional power Doppler in the assessment of ovarian tumors. Int J Gynaecol Obstet. 2007; 99(3):201-205.

85. Cohen LS, Escobar PF, Scharm C, Glimco B, Fishman DA. Three-dimensional ultrasound power Doppler improves the diagnostic accuracy for ovarian cancer prediction. Gynecol Oncol. 2001;82(1):40-48.

86. Marret H, Sauget S, Giraudeau B, Body G, Tranquart F. Power Doppler vascularity index for predicting malignancy of adnexal masses. Ultrasound Obstet Gynecol. 2005;25(5):508-513.

87. Alcázar JL, Castillo G. Comparison of 2-dimensional and 3-dimensional Power-Doppler imaging in complex adnexal masses for the prediction of ovarian cancer. Am J Obstet Gynecol. 2005;192(3):807-812.

88. Guerriero S, Alcázar JL, Ajossa S, et al. Transvaginal color Doppler imaging in the detection of ovarian cancer in a large study population. Int J Gynecol Cancer. 2010;20(5):781-786.

89. Konerding MA, Malkusch W, Klapthor B, et al. Evidence for characteristic vascular patterns in solid tumours: quantitative studies using corrosion casts. Br J Cancer. 1999;80(5-6):724-732.

90. Kurjak A, Kupesic S, Sparac V, Bekavac I. Preoperative evaluation of pelvic tumors by Doppler and three-dimensional sonography. J Ultrasound Med. 2001;20(8):829-840.

91. Kurjak A, Kupesic S, Anic T, Kosuta D. Three-dimensional ultrasound and power Doppler improve the diagnosis of ovarian lesions. Gynecol Oncol. 2000;76(1):28-32.

92. Kupesic S, Kurjak A. Contrast-enhanced three-dimensional power Doppler sonography for differentiation of adnexal masses. Obstet Gynecol. 2000;96(3):452-458.

93. Sladkevicius P, Jokubkiene L, Valentin L. Contribution of morphological assessment of the vessel tree by three-dimensional ultrasound to a correct diagnosis of malignancy in ovarian masses. Ultrasound Obstet Gynecol. 2007;30(6):874-882.

94. Alcázar JL, Cabrera C, Galván R, Guerriero S. Three-dimensional power Doppler vascular network assessment of adnexal masses: intraobserver and interobserver agreement analysis. $J$ Ultrasound Med. 2008;27(7):997-1001.

95. Dai SY, Hata K, Inubashiri E, et al. Does three-dimensional power Doppler ultrasound improve the diagnostic accuracy for the prediction of adnexal malignancy? J Obstet Gynaecol Res. 2008;34(3): 364-370.

96. Mansour GM, El-Lamie IK, El-Sayed HM, et al. Adnexal mass vascularity assessed by 3-dimensional power Doppler: does it add to the risk of malignancy index in prediction of ovarian malignancy?: four hundred-case study. Int J Gynecol Cancer. 2009;19(5): 867-872.

97. Alcázar JL, Mercé LT, Garcia Manero M. Three-dimensional power Doppler vascular sampling: a new method for predicting ovarian cancer in vascularized complex adnexal masses. $J$ Ultrasound Med. 2005;24(5):689-696.

98. Alcázar JL, Rodriguez D, Royo P, Galván R, Ajossa S, Guerriero S. Intraobserver and interobserver reproducibility of 3-dimensional power Doppler vascular indices in assessment of solid and cystic-solid adnexal masses. J Ultrasound Med. 2008;27(1):1-6.

99. Testa AC, Ajossa S, Ferrandina G, et al. Does quantitative analysis of three-dimensional power Doppler angiography have a role in the diagnosis of malignant pelvic solid tumors? A preliminary study. Ultrasound Obstet Gynecol. 2005;26(1):67-72.

100. Geomini PM, Kluivers KB, Moret E, Bremer GL, Kruitwagen RF, Mol BW. Evaluation of adnexal masses with three-dimensional ultrasonography. Obstet Gynecol. 2006;108(5):1167-1175.

101. Jokubkiene L, Sladkevicius P, Valentin L. Does three-dimensional power Doppler ultrasound help in discrimination between benign and malignant ovarian masses? Ultrasound Obstet Gynecol. 2007; 29(4):215-225.

102. Alcázar JL, Guerriero S. Three-dimensional power Doppler in ovarian tumors. Ultrasound Obstet Gynecol. 2007;29(6):718-719. 
103. Kudla MJ, Timor-Tritsch IE, Hope JM, et al. Spherical tissue sampling in 3-dimensional power Doppler angiography: a new approach for evaluation of ovarian tumors. J Ultrasound Med. 2008;27(3):425-433.

104. Ohel I, Sheiner E, Aricha-Tamir B, et al. Three-dimensional power Doppler ultrasound in ovarian cancer and its correlation with histology. Arch Gynecol Obstet. 2010;281(5):919-925.

105. Alcázar JL, Prka M. Evaluation of two different methods for vascular sampling by three-dimensional power Doppler angiography in solid and cystic-solid adnexal masses. Ultrasound Obstet Gynecol. 2009;33(3):349-354.

106. Kudla M, Alcázar JL. Does the size of three-dimensional power Doppler spherical sampling affect the interobserver reproducibility of measurements of vascular indices in adnexal masses? Ultrasound Obstet Gynecol. 2009;34(6):732-734.

107. Alcázar JL, Rodriguez D. Three-dimensional power Doppler vascular sonographic sampling for predicting ovarian cancer in cystic-solid and solid vascularized masses. J Ultrasound Med. 2009;28(3):275-281.

108. Kudla MJ, Alcázar JL. Does sphere volume affect the performance of three-dimensional power Doppler virtual vascular sampling for predicting malignancy in vascularized solid or cystic-solid adnexal masses? Ultrasound Obstet Gynecol. 2010;35(5):602-608.
109. Kudla M, Alcázar JL. 3DPD imaging of ovarian pathology advantages and limitation of the method. How can we standardize the results? Donald School J Ultrasound Obstet Gynecol. 2009;3: 47-53.

110. Kudla MJ, Alcázar JL. Spatiotemporal image correlation using highdefinition flow: a new method for assessing ovarian vascularization. J Ultrasound Med. 2010;29(10):1469-1474.

111. Martins WP, Welsh AW, Lima JC, Nastri CO, Raine-Fenning NJ. The "Volumetric" Pulsatility Index as Evaluated by Spatiotemporal Imaging Correlation (STIC): A Preliminary Description of a Novel Technique, Its Application to the Endometrium and an Evaluation of Its Reproducibility. Ultrasound Med Biol. 2011;37(12): 2160-2168.

112. Kudla MJ, Alcázar JL. Spatial-Temporal Image Correlation (STIC) with spherical sampling and High Definition Flow - new 4D method for assessment of tissue vascularization changes during cardiac cycle: Reproducibility analysis. J Ultrasound Med. 2012;31(1):73-80.
Reports in Medical Imaging

\section{Publish your work in this journal}

Reports in Medical Imaging is an international, peer-reviewed, open access journal publishing original research, reports, reviews and commentaries on all areas of medical imaging. The manuscript management system is completely online and includes a very quick and fair peer-review system, which is all easy to use.

\section{Dovepress}

Visit http://www.dovepress.com/testimonials.php to read real quotes from published authors. 